\title{
Vivências de uma capacitação e seu impacto no conhecimento de manipuladores de alimentos: relato de experiência extensionista
}

Experiences of training and its impact on the knowledge of food handlers: extension experience report

Experiencias de formación y su impacto en el conocimiento de los manipuladores de alimentos: informe de experiencia de extensión

Jade Maria Gordiano da Silva ORCID: https://orcid.org/0000-0002-1853-3513 Universidade Estadual do Ceará, Brasil E-mail: jade.gordiano@aluno.uece.br Derlange Belizário Diniz ORCID: https://orcid.org/0000-0002-5492-5282 Universidade Estadual do Ceará, Brasil

E-mail: derlange.diniz@uece.br Sara Castro Marques ORCID: https://orcid.org/0000-0001-8914-2643 Universidade Estadual do Ceará, Brasil E-mail: sara.marques@aluno.uece.br

Kaluce Gonçalves de Sousa Almondes ORCID: https://orcid.org/0000-0003-2694-1629 Universidade Estadual do Ceará, Brasil E-mail: kaluce.almondes@uece.br Dionisia Nagahama ORCID: https://orcid.org/0000-0003-4264-4771 Instituto Nacional de Pesquisas da Amazônia, Brasil E-mail: dionenagahama@gmail.com

Márcia Rubia Duarte Buchweitz ORCID: https://orcid.org/0000-0002-4403-1306 Universidade Federal de Pelotas, Brasil

E-mail: marciabuchweitz@yahoo.com.br Claisa Andrea Freitas Rabelo

ORCID: https://orcid.org/0000-0001-5148-4357 Universidade Estadual do Ceará, Brasil E-mail: claisa.freitas@uece.br

\begin{abstract}
Resumo
O presente artigo objetiva descrever as experiências do "Curso de Formação de Manipuladores de Alimentos de Escolas Municipais de Fortaleza" e avaliar o impacto na aquisição de conhecimentos sobre Alimentação e Nutrição (AN) e Boas Práticas de Manipulação (BPM). Este trabalho possui uma abordagem qualitativa e quantitativa para melhor interpretação das repercussões relacionadas à realização da capacitação. O Curso foi ofertado para 600 profissionais de 527 instituições vinculadas ao Programa Nacional de Alimentação Escolar, tendo discentes da Universidade Estadual do Ceará, em parceria com nutricionistas da Célula de Alimentação Escolar da Secretaria Municipal de Educação, como facilitadores das atividades. No primeiro e no último dia de Curso, foi aplicado um questionário para avaliar o nível de conhecimento dos participantes em AN e BPM. Entre os 28 itens desse questionário, houve diferença estatisticamente significativa nas respostas corretas de 20 itens $(71,42 \%)$, sendo 11 $(73,3 \%)$ da temática AN e $9(69,2 \%)$ de BPM. O aumento do percentual de respostas corretas após a capacitação sugere incremento no nível de conhecimento dos manipuladores de alimentos. Com a realização das atividades, focando em estratégias mais lúdicas e integrativas para favorecer o processo de aprendizagem, foi percebida a satisfação e o engajamento dos participantes ao compartilharem suas vivências e práticas. Como atividade de Extensão Universitária, a realização do Curso proporcionou benefícios aos graduandos, aos profissionais nutricionistas e à sociedade civil.
\end{abstract}

Palavras-chave: Segurança alimentar e nutricional; Alimentação escolar; Manipulação de alimentos; Capacitação. 


\begin{abstract}
This article aims to describe the experiences of the "Training Course for Food Handlers at Municipal Schools in Fortaleza" and to assess the impact on the acquisition of knowledge about Food and Nutrition (NA) and Good Handling Practices (BPM). This work has a qualitative and quantitative approach for a better interpretation of the repercussions related to the training. The course was offered to 600 professionals from 527 institutions linked to the National School Feeding Program, with students from the State University of Ceará, in partnership with nutritionists from the School Feeding Cell of the Municipal Department of Education, as facilitators of the activities. On the first and last day of the course, a questionnaire was applied to assess the participants' level of knowledge in AN and BPM. Among the 28 items of this questionnaire, there was a statistically significant difference in the correct answers of 20 items $(71.42 \%), 11(73.3 \%)$ of the AN theme and $9(69.2 \%)$ of BPM. The increase in the percentage of correct answers after training suggests an increase in the level of knowledge of food handlers. With the carrying out of activities, focusing on more playful and integrative strategies to favor the learning process, the satisfaction and engagement of participants was perceived when sharing their experiences and practices. As a University Extension activity, the completion of the Course provided benefits to undergraduates, nutritionists and civil society.
\end{abstract}

Keywords: Food and nutrition security; School feeding; Food handling; Training.

\title{
Resumen
}

Este artículo tiene como objetivo describir las experiencias del "Curso de Capacitación para Manejadores de Alimentos en Escuelas Municipales de Fortaleza" y evaluar el impacto en la adquisición de conocimientos sobre Alimentación y Nutrición (NA) y Buenas Prácticas de Manejo (BPM). Este trabajo tiene un enfoque cualitativo y cuantitativo para una mejor interpretación de las repercusiones relacionadas con la formación. El curso se ofreció a 600 profesionales de 527 instituciones vinculadas al Programa Nacional de Alimentación Escolar, con estudiantes de la Universidad Estadual de Ceará, en alianza con nutricionistas de la Célula de Alimentación Escolar del Departamento Municipal de Educación, como facilitadores de las actividades. El primer y último día del curso se aplicó un cuestionario para evaluar el nivel de conocimiento de los participantes en AN y BPM. Entre los 28 ítems de este cuestionario, hubo una diferencia estadísticamente significativa en las respuestas correctas de 20 ítems (71,42\%), $11(73,3 \%)$ del tema AN y $9(69,2 \%)$ del BPM. El aumento en el porcentaje de respuestas correctas después de la capacitación sugiere un aumento en el nivel de conocimiento de los manipuladores de alimentos. Con la realización de actividades, enfocándose en estrategias más lúdicas e integradoras para favorecer el proceso de aprendizaje, se percibió la satisfacción y el compromiso de los participantes al compartir sus experiencias y prácticas. Como actividad de Extensión Universitaria, la realización del Curso brindó beneficios a los estudiantes de pregrado, nutricionistas y sociedad civil.

Palabras clave: Seguridad alimentaria y nutricional; Alimentación escolar; Manipulación de alimentos; Capacitación.

\section{Introdução}

No Brasil, ainda vivemos sob a dualidade de desafios quanto à insegurança alimentar da população, coexistindo a fome e a alta prevalência de doenças crônicas não transmissíveis (DCNT), questões que permeiam inclusive o âmbito escolar (Rabelo et al., 2020).

Como exemplo de política pública voltada para a segurança alimentar e nutricional (SAN), destaca-se o Programa Nacional de Alimentação Escolar (PNAE), assim denominado a partir de 1979, como a mais duradoura e abrangente na área (Santos et al., 2007). Entre as principais ações do PNAE, destacam-se a oferta alimentar para estudantes de escolas públicas e a inclusão de ações de educação alimentar e nutricional (EAN) no currículo escolar (Brasil, 2009).

Baseada nessa assistência alimentar suplementar, a aplicação do PNAE possibilita crescimento e desenvolvimento no aspecto individual e oferece campo para ensino-aprendizagem com foco na promoção da saúde coletiva (Libermann \& Bertolini, 2015). Considerando a clientela atendida e a sua vulnerabilidade nutricional e socioeconômica, a preocupação com a SAN é necessária e constante (Soares et al., 2018; Lopes, Pinto, Costa, Mascarenhas \& Aquino, 2015).

A execução do PNAE, ao objetivar a oferta de alimentos saudáveis e seguros, permite a garantia do Direito Humano à Alimentação Adequada (DHAA) e a consecução de ações relacionadas aos Objetivos de Desenvolvimento do Milênio (ODM) pertinentes à alimentação (Villar, Schwartzman, Januario \& Ramos, 2013).

Com validade até 2015, os ODM se aperfeiçoaram em Objetivos do Desenvolvimento Sustentável (ODS), programados até 2030. Dentre eles, o alcance dos ODS que abrangem a erradicação da fome (ODS 2), promoção da saúde (ODS 3) e educação de qualidade (ODS 4) podem ser interconectados na execução do PNAE: a oferta de refeições, 
minimizando a insegurança alimentar, atua como estratégia de incentivo à continuidade dos estudos e serve como plataforma para atividades lúdicas que abordem a EAN, fortalecendo melhores hábitos alimentares e, assim, melhores padrões de saúde (Valentim, Dias \& Paixão, 2019).

A escola é local viabilizador do desenvolvimento e da articulação de ações transversais promotoras de saúde, com capacidade real de impacto nos hábitos alimentares. Assim, a alimentação escolar pode ser reconhecida como uma estratégia pedagógica efetiva ao garantir a SAN e ser palco para ações de EAN (Camozzi, Monego, Menezes \& Silva, 2015).

Para que essa complexa responsabilidade seja cumprida, é necessária a ação colaborativa de diversos atores envolvidos na execução do PNAE. Entre eles, o nutricionista representa o profissional responsável técnico encarregado da coordenação, desenvolvimento e realização das ações de EAN, devendo atuar de forma harmônica com a gestão da escola (Silva, Monego, Sousa \& Almeida, 2018).

Em conjunto com a atuação do nutricionista, é ressaltada a atuação do manipulador de alimentos, o produtor direto das refeições, o qual possui significativa responsabilidade pela segurança higiênico-sanitária dos alimentos desde o recebimento até o momento da distribuição e, assim, atua na prevenção da ocorrência de doenças transmitidas por alimentos (DTA) (Garcia \& Centenaro, 2016; Husain, Muda, Jamil, Hanafi \& Rahman, 2016).

Além da responsabilidade com a qualidade higiênico-sanitária da refeição produzida, o manipulador de alimentos também está envolvido na qualidade nutricional desta. Deve, assim, compreender sobre variadas formas de preparo e apresentação dos alimentos, composições harmônicas para os cardápios, além do uso consciente de ingredientes culinários, como sal, açúcar e gorduras (Camozzi, Monego, Menezes \& Silva, 2015).

Desse modo, é revelado o valioso papel desse profissional na formação de hábitos alimentares e de vida saudáveis (Scarparo, Baldasso, Lopes, Rockett \& Venzke, 2017), ao atuar diretamente no preparo de refeições nutricionalmente adequadas e podendo atuar também na conscientização dos alunos sobre a prevenção de DCNT.

Em suma, por ser um profundo conhecedor do cenário físico e dos aspectos sociais e mentais dos estudantes, o papel do manipulador de alimentos como educador em saúde deve ser considerado e valorizado (Fernandes, Fonseca \& Silva, 2014), devendo este ser público-alvo de programas permanentes de EAN (Camozzi, Monego, Menezes \& Silva, 2015).

A Resolução de Diretoria Colegiada (RDC) nº 216 da Agência Nacional de Vigilância Sanitária (ANVISA) estabelece que os responsáveis pela manipulação de alimentos devem receber minimamente capacitações abordando as temáticas contaminantes alimentares, DTA, manipulação higiênica dos alimentos e boas práticas (Brasil, 2004).

Acerca disso, é evidente o maior enfoque das capacitações no aspecto higiênico-sanitário dos alimentos, pauta que permanece urgente. Toda a equipe responsável pelo preparo das refeições deve ser conhecedora das normas que regem a manipulação adequada dos alimentos, considerando aspectos de higiene do local, dos utensílios e equipamentos, dos recursos humanos, além de quesitos sobre transporte seguro, recebimento e armazenamento (Ferreira, de Lima \& Aguiar, 2020).

No entanto, ressalta-se também a importância dessas capacitações englobarem ainda a exposição e a discussão de estratégias para promoção da alimentação saudável, além da reflexão e do fortalecimento do papel educador do manipulador de alimentos.

O desenvolvimento e a execução de capacitações condizentes com seus objetivos devem considerar a real busca do aprendizado, não somente a transmissão de conhecimentos. Por isso, destacam-se o aprimoramento e a aplicação de metodologias que envolvam atitudes de criticidade, reflexão, consciência individual e coletiva, além da criatividade na proposição de soluções viáveis (Pallos, Souza, Oberlender, Colpa \& Bueno da Silva, 2020).

Diante do exposto, o presente estudo objetiva descrever as experiências do "Curso de Formação de Manipuladores de Alimentos de Escolas Municipais de Fortaleza" e avaliar seu impacto na aquisição de conhecimentos sobre Alimentação e Nutrição (AN) e Boas Práticas de Manipulação (BPM). 


\section{Metodologia}

Este trabalho descreve as experiências da atividade extensionista "Curso de Formação de Manipuladores de Alimentos de Escolas Municipais de Fortaleza” através de uma abordagem qualitativa e quantitativa, a qual permite uma melhor interpretação da intervenção realizada (Santos et al., 2017).

O "Curso de Formação de Manipuladores de Alimentos de Escolas Municipais de Fortaleza" compôs o projeto de pesquisa "Capacitação de professores, manipuladores de alimentos e agricultores familiares para a promoção da alimentação saudável na escola: um estudo multicêntrico". Foi realizado em julho de 2017 em salas de aula, no Restaurante Universitário e no Auditório Central da Universidade Estadual do Ceará (UECE) - campus Itaperi, sendo uma parceria entre o Projeto de Extensão "Comida Saudável: da escolha ao preparo, com aproveitamento integral dos alimentos", o Laboratório de Segurança Alimentar e Nutricional (LABSAN), o Programa de Pós-graduação em Nutrição e Saúde (PPGNS) da UECE e a Célula de Alimentação Escolar da Secretaria Municipal de Educação (SME) de Fortaleza.

Previamente, foi realizado o planejamento das atividades a serem desenvolvidas, com elaboração de planos de aula, produção de slides e materiais educativos, simulação das dinâmicas, estruturação de questionário avaliativo do conhecimento sobre AN e BPM, além do treinamento da equipe de facilitadores.

Após levantamento do quantitativo de profissionais presentes nas 527 instituições escolares municipais, 600 manipuladores de alimentos foram convocados a participar da capacitação. Estes foram divididos em grupos de até 30 indivíduos, compondo 10 turmas no turno da manhã e 10 no turno da tarde, durante o período de cinco dias, com carga horária final de 20 horas. Cada turma contou com três facilitadores, sendo ao total: 10 nutricionistas da SME, 14 nutricionistas mestrandas do PPGNS e 23 graduandos do Curso de Nutrição da UECE.

A capacitação se dividiu em dois blocos temáticos educativos, abrangendo conhecimentos sobre AN e BPM na Alimentação Escolar. Os materiais didáticos produzidos foram norteados por importantes referenciais teóricos, como o "Guia alimentar para a população brasileira" (Brasil, 2014), o "Programa 5 ao dia" vinculado à Organização Mundial da Saúde (OMS) e difundido no Brasil pelo Instituto Brasileiro de Orientação Alimentar (IBRA) (Brasil, 2005), a RDC n 216/2004 que dispõe sobre o Regulamento Técnico de Boas Práticas para Serviços de Alimentação (Brasil, 2004) e a Cartilha sobre Boas Práticas de Manipulação baseada na RDC nº 216/2004 e elaborada pela Agência Nacional de Vigilância Sanitária (2004).

Como ferramenta educativa, abordando o tema higiene das mãos, foi realizada a análise microbiológica das mãos de manipuladores. A coleta das amostras foi feita pela técnica do esfregaço, com o auxílio de swabs estéreis umedecidos em solução salina $0,85 \%$ e aplicados no dorso, face palmar e entre os dedos de uma das mãos dos manipuladores. Em seguida, as amostras foram transportadas para o laboratório em caixa térmica contendo gelo reutilizável e imediatamente submetidas à plaqueamento em ágar padrão para contagem (PCA) de acordo com a metodologia de análise de contagem de aeróbios mesófilos descrita por Silva, et al. (2017). As placas foram incubadas a $37^{\circ} \mathrm{C}$ por 48 horas e expostas para observação pelos manipuladores, os quais foram orientados a comparar a quantidade de Unidades Formadoras de Colônias (UFC) das placas provenientes de mãos lavadas e não lavadas.

Quanto à mensuração do nível de conhecimento dos manipuladores de alimentos, foi construído um questionário avaliativo por meio da contribuição coletiva de pesquisadores de vários estados componentes do projeto multicêntrico. Esse questionário foi estruturado em 22 questões ( 9 sobre AN e 13 sobre BPM), abrangendo 20 de múltipla escolha (18 com opções a, b, c, d, e; 1 com certo, errado, não sei/não tenho certeza; 1 com muito, pouco, não sei/não tenho certeza), 1 dicotômica (sim e não) e 1 de resposta aberta (quantidade). Foi realizada a sua validação prévia e, no presente estudo, ele foi aplicado em dois momentos: antes (pré-teste) e após (pós-teste) a capacitação.

Do total de participantes, 497 (82,83\%) responderam ao questionário avaliativo antes e após a capacitação, compreendendo a amostra final, representada majoritariamente por mulheres $(94,97 \%)$. 
Os dados coletados nesse questionário foram expressos como frequências e percentuais e submetidos à análise estatística para testar a mudança nas respostas dos participantes entre o pré-teste e o pós-teste e, assim, avaliar o impacto da capacitação no conhecimento. Foi utilizado o teste estatístico de McNemar, para tabelas de contingência 2x2, e o de McNemarBowker, para tabelas de contingência maiores que $2 \times 2$, no software $\mathrm{R}$ versão 3.2.2. Os dados foram considerados significativos com valores de p menores ou iguais a 0,05 .

Os participantes foram convidados a participar voluntariamente da pesquisa, assinando um Termo de Consentimento Livre Esclarecido (TCLE) no primeiro dia de atividades. A pesquisa cumpriu as recomendações da Resolução 466/2012 do Conselho Nacional de Saúde quanto aos aspectos éticos de pesquisas que envolvem seres humanos (Brasil, 2013). O projeto foi cadastrado e aceito na Plataforma Brasil, encaminhado ao Comitê de Ética em Pesquisa (CEP) do Instituto Nacional de Pesquisas da Amazônia (INPA/MCT/PR) e encontra-se aprovado sob parecer nº 1.396.744.

\section{Resultados e Discussão}

\subsection{Experiências do Curso de Formação de Manipuladores de Alimentos de Escolas Municipais de Fortaleza}

A abertura do primeiro dia foi realizada no Auditório Central da UECE, iniciando com reflexões sobre a importância da capacitação na prática profissional dos manipuladores de alimentos presentes. A solenidade contou, inclusive, com a presença de autoridades da UECE e da SME.

Após a distribuição em turmas, os participantes foram acolhidos nas salas de aula com dinâmicas de integração para estimular o bom relacionamento entre eles. Diferentes dinâmicas também foram aplicadas nos quatro dias seguintes, objetivando iniciar as atividades de forma leve e descontraída.

A equipe da SME iniciou com uma explanação sobre conhecimentos relacionados ao PNAE. Em seguida, foi aplicado o questionário pré-teste para avaliar o conhecimento prévio dos participantes. Devido dificuldades de leitura e letramento, alguns manipuladores de alimentos necessitaram de mais apoio dos facilitadores, o que demandou bastante tempo para esse momento.

Também no primeiro dia, monitores da disciplina de Microbiologia de Alimentos do Curso de Nutrição da UECE realizaram a coleta de amostras da superfície das mãos de manipuladores para análise microbiológica. Dois participantes foram escolhidos aleatoriamente em cada turma dos dois turnos, sendo o primeiro participante representativo do momento anterior à lavagem das mãos e o segundo representativo do momento posterior.

No segundo dia de capacitação, foram realizadas sequencialmente seis atividades com foco na temática AN:

- Dinâmica "Prato Saudável";

- "Programa 5 ao dia": explicação sobre os benefícios do consumo de frutas e hortaliças para o aporte diário adequado de nutrientes;

- "Guia alimentar para a população brasileira": explicação sobre a diferença do grau de processamento dos alimentos (in natura, processados e ultraprocessados);

- Dinâmica "Teor de Açúcar dos Alimentos";

- Dinâmica "Semáforo dos Alimentos";

- Dinâmica "Análise de Rótulos de Alimentos".

No Quadro 1, são apresentados o objetivo, a descrição e o material utilizado nas dinâmicas mencionadas. 
Quadro 1 - Dinâmicas sobre "Alimentação e Nutrição" realizadas na capacitação de manipuladores de alimentos.

Fortaleza/CE. 2021.

\begin{tabular}{|c|c|c|c|}
\hline Dinâmica & Objetivo & Descrição & Material \\
\hline $\begin{array}{c}\text { Prato } \\
\text { Saudável }\end{array}$ & $\begin{array}{l}\text { Informar como compor uma } \\
\text { refeição saudável equilibrando } \\
\text { as proporções e as fontes de } \\
\text { nutrientes adequadamente } \\
\text { (vegetais, frutas, carnes/ovos, } \\
\text { leguminosas e carboidratos) }\end{array}$ & $\begin{array}{l}\text { Os participantes foram divididos em equipes de até } 5 \text { integrantes. } \\
\text { Cada equipe, por vez, foi orientada a montar uma refeição } \\
\text { saudável (almoço) de acordo com seus conhecimentos iniciais, } \\
\text { utilizando uma cartolina em formato de prato, imagens de diversos } \\
\text { alimentos e fita adesiva. Em seguida, os facilitadores fizeram uma } \\
\text { exposição sobre como e por que montar um prato saudável } \\
\text { equilibrando as proporções e fontes de nutrientes ( } 50 \% \text { de vegetais } \\
\text { - crus e cozidos, } 25 \% \text { de carboidratos de preferência integrais, } \\
25 \% \text { de proteína animal e proteína vegetal, } 1 \text { fruta de sobremesa) e } \\
\text { promoveram a avaliação e a discussão quanto aos pratos montados } \\
\text { pelas equipes (Imagem A). }\end{array}$ & $\begin{array}{l}\text { Para a equipe: } \\
\text { - } 1 \text { cartolina em } \\
\text { formato de prato } \\
\text { - Imagens de } \\
\text { alimentos } \\
\text { - Fita adesiva } \\
\text { - Slides } \\
\text { - Notebook } \\
\text { - Datashow }\end{array}$ \\
\hline $\begin{array}{l}\text { Teor de } \\
\text { Açúcar } \\
\text { dos } \\
\text { Alimentos }\end{array}$ & $\begin{array}{l}\text { Impactar quanto à quantidade } \\
\text { de açúcar encontrada nos } \\
\text { alimentos ultraprocessados }\end{array}$ & $\begin{array}{l}\text { Foi exposto aos participantes um painel com imagens de alimentos } \\
\text { (frutas e verduras, refrigerante, biscoito recheado, achocolatado, } \\
\text { massa para mingau, suco industrializado) e a quantidade de açúcar } \\
\text { contida neles, representada em colheres de chá. Foi estimulada a } \\
\text { discussão acerca das diferenças visualizadas entre alimentos in } \\
\text { natura e ultraprocessados (Imagem B). }\end{array}$ & $\begin{array}{c}\text { - Painel Teor de } \\
\text { Açúcar dos Alimentos }\end{array}$ \\
\hline $\begin{array}{l}\text { Semáforo } \\
\text { dos } \\
\text { Alimentos }\end{array}$ & $\begin{array}{l}\text { Sensibilizar os participantes } \\
\text { quanto ao consumo alimentar } \\
\text { excessivo de sal e gordura } \\
\text { Relacionar com a prevenção do } \\
\text { desenvolvimento de DCNT e } \\
\text { anemia }\end{array}$ & $\begin{array}{l}\text { Os participantes foram divididos em equipes de até } 5 \text { integrantes. } \\
\text { Cada equipe, por vez, foi orientada a construir um semáforo dos } \\
\text { alimentos, de acordo com seus conhecimentos iniciais, associando } \\
\text { e dispondo as imagens nas cores correspondentes ao seu teor de } \\
\text { sal e gordura (verde = baixo teor, amarelo = teor moderado, } \\
\text { vermelho = alto teor). Em seguida, os facilitadores fizeram uma } \\
\text { exposição sobre as posições "corretas" de cada alimento disposto, } \\
\text { esclarecendo dúvidas (Imagem C). Também foi realizada a } \\
\text { exposição de slides sobre a temática DCNT e anemia, reforçando } \\
\text { a } \\
\text { importância do consumo equilibrado de sal, gordura e açúcar para } \\
\text { a prevenção do desenvolvimento de doenças. }\end{array}$ & $\begin{array}{l}\text { Para a equipe: } \\
\text { - Painel Semáforo } \\
\text { - Imagens de } \\
\text { alimentos } \\
\text { - Fita adesiva } \\
\text { - Slides } \\
\text { - Notebook } \\
\text { - Datashow }\end{array}$ \\
\hline $\begin{array}{c}\text { Análise } \\
\text { de } \\
\text { Rótulos } \\
\text { de } \\
\text { Alimentos }\end{array}$ & $\begin{array}{l}\text { Proporcionar a compreensão } \\
\text { sobre informações contidas nos } \\
\text { rótulos alimentares e estimular } \\
\text { a leitura rotineira }\end{array}$ & $\begin{array}{l}\text { Cada participante recebeu um rótulo de alimento utilizado } \\
\text { frequentemente na Alimentação Escolar para observação e } \\
\text { discussão de informações como validade, modo de preparo e lista } \\
\text { de ingredientes. Cada parte do rótulo era explicada, com o suporte } \\
\text { da exposição de slides, e os participantes acompanhavam na } \\
\text { embalagem recebida. Foi reforçada a importância da leitura } \\
\text { rotineira dos rótulos de alimentos comprados em mercados, } \\
\text { mercearias, etc. }\end{array}$ & $\begin{array}{l}\text { Para cada participante: } \\
\text { - Embalagens de } \\
\text { alimentos } \\
\text { - Slides } \\
\text { - Notebook } \\
\text { - Datashow }\end{array}$ \\
\hline
\end{tabular}

Fonte: Autores (2021).

No terceiro dia de capacitação, foram realizadas atividades com foco na temática BPM, através da exposição dialogada sobre os seguintes assuntos:

- Intoxicações alimentares. Reportagens de surtos alimentares no Brasil;

- Microrganismos, DTA e controle de perigos. Vídeo "Jogo dos Sete Erros na Cozinha” - Doutor Bactéria;

- $\quad$ Perecibilidade e armazenamento correto dos alimentos;

- Recebimento e armazenamento de alimentos, utensílios e gás. Planilhas de recebimento de alimentos e gás;

- $\quad$ Manejo de resíduos e de óleo;

- Limpeza e desinfecção dos alimentos. Diferença entre limpeza e desinfecção. Desinfecção correta de

hortaliças;

- $\quad$ Higienização de utensílios, equipamentos e ambiente. Frequência e preenchimento de planilhas; 
- $\quad$ Higiene do trabalhador e lavagem das mãos;

- Refrigeração, congelamento e descongelamento dos alimentos.

Nesse dia, também foram realizadas as dinâmicas "Jogo dos Erros” e "Organizando a Geladeira”. No Quadro 2, são apresentados o objetivo, a descrição e o material utilizado nas dinâmicas mencionadas.

Quadro 2 - Dinâmicas sobre "Boas Práticas de Manipulação" realizadas na capacitação de manipuladores de alimentos.

Fortaleza/CE. 2021.

\begin{tabular}{|c|c|c|c|}
\hline Dinâmica & Objetivo & Descrição & Material \\
\hline $\begin{array}{c}\text { Jogo dos } \\
\text { Erros }\end{array}$ & $\begin{array}{l}\text { Identificar erros na } \\
\text { manipulação, } \\
\text { armazenamento e } \\
\text { recebimento dos } \\
\quad \text { alimentos }\end{array}$ & $\begin{array}{l}\text { Através da projeção de imagens, foram expostas aos } \\
\text { participantes situações representando erros durante o pré- } \\
\text { preparo, preparo, pós-preparo, armazenamento e distribuição } \\
\text { dos alimentos. Os facilitadores incentivaram a identificação de } \\
\text { tais erros e a discussão sobre como corrigi-los. }\end{array}$ & $\begin{array}{l}\text { - Slides } \\
\text { - Notebook } \\
\text { - Datashow }\end{array}$ \\
\hline $\begin{array}{c}\text { Organizando } \\
\text { a Geladeira }\end{array}$ & $\begin{array}{l}\text { Demonstrar a forma } \\
\text { correta de armazenar os } \\
\text { alimentos na geladeira }\end{array}$ & $\begin{array}{l}\text { Foi projetada na parede a imagem de uma geladeira aberta e } \\
\text { vazia. Os participantes foram orientados a colar imagens de } \\
\text { alimentos (in natura, refrigerados, congelados) nos locais que } \\
\text { julgassem corretos, de acordo com seus conhecimentos } \\
\text { iniciais. Em seguida, foram discutidas as escolhas de locais } \\
\text { para armazenamento, explicando o porquê de cada (fora da } \\
\text { geladeira, sob refrigeração ou congelamento) (Imagem D). }\end{array}$ & $\begin{array}{l}\text { - Imagens de alimentos } \\
\text { (refrigerados e congelados) } \\
\text { - Slides } \\
\text { - Notebook } \\
\text { - Datashow }\end{array}$ \\
\hline
\end{tabular}

Fonte: Autores (2021).

Na Figura 1, são demonstrados exemplos de materiais desenvolvidos pelos facilitadores e utilizados em algumas das dinâmicas do Curso. 
Figura 1 - Materiais desenvolvidos para dinâmicas da capacitação de manipuladores de alimentos. Fortaleza/CE. 2021.

A

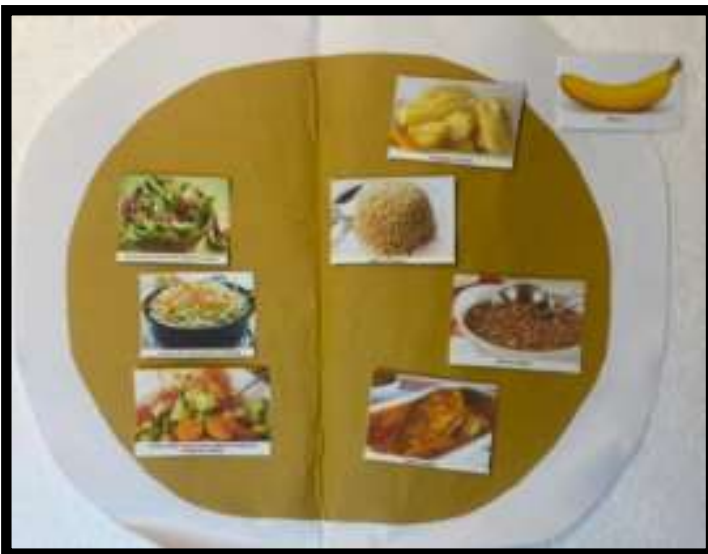

C

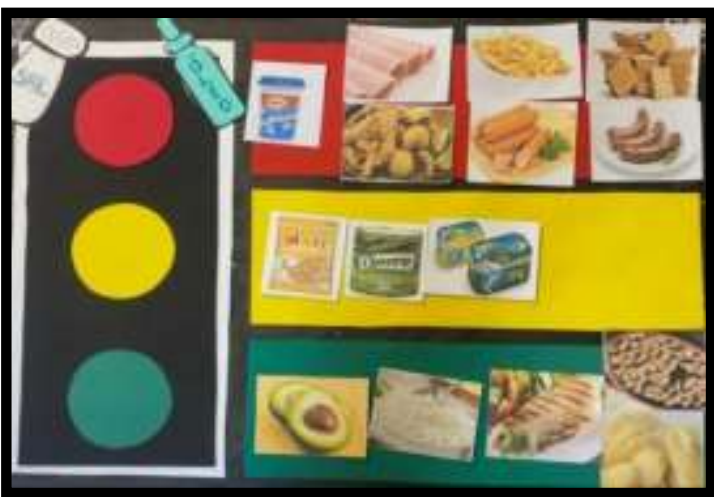

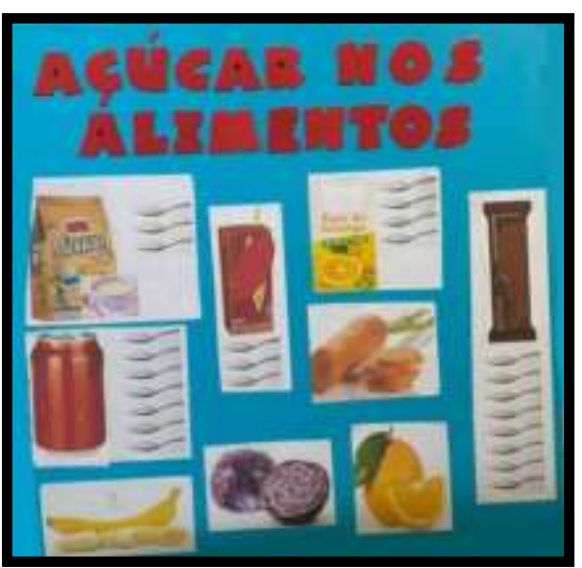

B

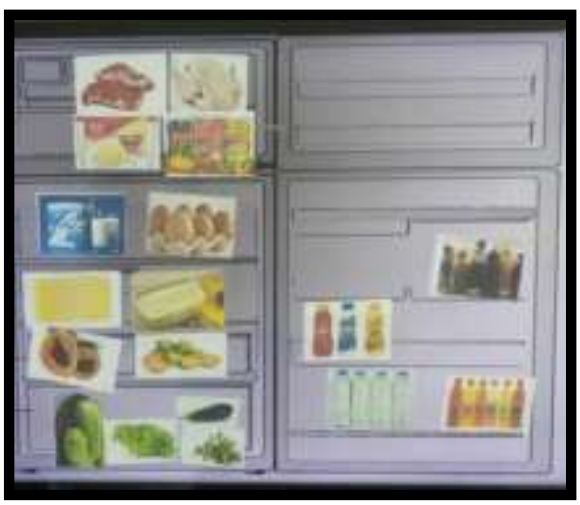

D

A - "Prato Saudável". B - Painel demonstrativo do "Teor de Açúcar dos Alimentos". C - "Semáforo dos Alimentos". D - "Organizando a Geladeira".

Fonte: Autores (2021)

Abrangendo o tema higiene do manipulador de alimentos e lavagem das mãos, foram apresentadas as placas de petri inoculadas com as amostras coletadas das mãos dos manipuladores no primeiro dia de capacitação. Para a adequada observação do crescimento de bactérias nas placas, os participantes foram orientados quanto ao conceito e à identificação de colônias bacterianas e sobre a relação diretamente proporcional entre a quantidade de colônias e a contaminação das mãos. Foi solicitado ao grupo que observasse e comparasse o crescimento de colônias bacterianas nas placas correspondentes às mãos que foram ou não higienizadas. Os participantes constataram maior quantidade de colônias, ou seja, maior crescimento de aeróbios mesófilos e, consequentemente, maior contaminação nas amostras correspondentes a não higienização das mãos.

Importante salientar que esses resultados já eram esperados, conforme evidências da literatura. Estudos realizados em escolas públicas do Maranhão (Oliveira et al., 2019) e de Minas Gerais (Del'Arcos, Santos, Gonçalves, Villanoeva \& Dell'Isola, 2020) demonstraram que a maioria ou todas as amostras das mãos de manipuladoras de alimentos apresentavam condições higiênico-sanitárias inadequadas.

A dinâmica mostrou-se eficiente ao impactar quanto aos perigos microbiológicos carregados nas mãos e o perigo de contaminação de alimentos e utensílios. A aplicação de um exemplo prático trouxe maior sensibilização dos participantes, sendo recebido com surpresa e repulsa ao comentarem “Como algo que não podemos ver contamina assim?”, "Nossa, vai lavar a mão direito!”. Esse momento foi, assim, responsável por estimular a reflexão e a compreensão da importância da realização do procedimento adequado de higienização das mãos na prevenção de DTA.

O quarto dia da capacitação foi conduzido pelos facilitadores da SME com atividades teórico-práticas envolvendo o compartilhamento de conhecimentos e a discussão sobre o papel dos manipuladores de alimentos como educadores 
nutricionais, a importância das boas práticas dentro das unidades escolares, além de vídeos explicativos e exposição de produtos da agricultura familiar.

O quinto e último dia de capacitação contou com atividades conduzidas pelos facilitadores da SME abrangendo exposição de conhecimentos sobre técnica dietética, elaboração de fichas técnicas e definição de per capitas para alimentação saudável. Ao final, foi realizada a aplicação do questionário pós-teste para avaliar o conhecimento adquirido pelos participantes.

A capacitação também proporcionou momentos de exposição e apresentação de alimentos por fornecedores da alimentação escolar, além de demonstrações e orientações quanto ao preparo das refeições pelas nutricionistas facilitadoras.

Durante toda a capacitação, os facilitadores puderam observar que os participantes esboçavam contentamento em pertencerem ao grupo, conseguindo sociabilizar com colegas que trabalhavam próximos a eles, demonstrando estarem felizes em participar das atividades. Percebia-se que estar em ambiente acadêmico, por exemplo, representava orgulho e satisfação pessoal, contribuindo para mais atenção às explicações e maior envolvimento nas dinâmicas ao compartilharem suas vivências. Também o maior nível de assiduidade pode ser entendido como um indicador positivo do interesse e consequente melhor entendimento e atitude dos participantes.

Atividades de extensão universitária, como esta, contribuem diretamente na construção e qualificação profissional de acordo com a demanda do contexto social apresentado (Pissaia, Del Pino, Quartieri \& Marchi, 2018), ao problematizar questões, desenvolver novas habilidades e incentivar a busca de soluções.

A universidade e a sociedade podem, assim, se relacionar de forma transformadora, contemplando as complexas dimensões de cada ser. Para os alunos envolvidos na experiência, o desenvolvimento de habilidades transversais como flexibilidade, iniciativa, responsabilidade e trabalho em equipe contribuem com uma formação profissional crítica e cidadã (Souza \& Campos, 2019).

Com a realização da capacitação, foram observados benefícios para as comunidades escolares atendidas pelos manipuladores capacitados ao oportunizar o recebimento de refeições com maior qualidade sanitária e nutricional; para os manipuladores de alimentos ao desenvolver a autoestima e a valorização profissional, além do maior repertório de conhecimentos; e para os facilitadores da capacitação ao permitir a validação do aprendizado e a construção de mais experiências profissionais e relacionais.

\subsection{Impacto do Curso de Formação de Manipuladores de Alimentos de Escolas Municipais de Fortaleza no conhecimento dos participantes}

Quanto ao teste aplicado para investigar a mudança nas respostas entre o pré-teste e o pós-teste, foi encontrada diferença estatisticamente significativa nas respostas para 20 (71,42\%) dos 28 itens do questionário. A Tabela 1 apresenta a porcentagem de respostas assinaladas corretamente para cada item do questionário aplicado antes (pré-teste) e após (pós-teste) a capacitação. 
Tabela 1 - Comparação da porcentagem de respostas corretas no questionário avaliativo sobre AN e BPM. Fortaleza/CE. 2021.

\begin{tabular}{|c|c|c|c|}
\hline \multirow{2}{*}{$\begin{array}{c}\text { QUESTÕES } \\
\text { Alimentação e Nutrição }\end{array}$} & \multicolumn{3}{|c|}{ RESPOSTAS CORRETAS (\%) } \\
\hline & Pré-teste & Pós-teste & $\mathbf{p}^{\mathfrak{f}}$ \\
\hline 1. Uma opção de refeição mais saudável deve conter... & 89,94 & 96,78 & $<0,001^{\mathfrak{E}}$ \\
\hline 2. Qual das opções abaixo é exemplo de lanche mais saudável? & 74,25 & 79,28 & $0,046^{£}$ \\
\hline $\begin{array}{l}\text { 3. Das doenças abaixo relacionadas, qual delas não é causada por } \\
\text { uma alimentação errada? }\end{array}$ & 72,64 & 83,70 & $<0,001^{\mathfrak{f}}$ \\
\hline $\begin{array}{l}\text { 4. As frutas, legumes e verduras são essenciais para o bom } \\
\text { funcionamento intestinal, pois contém fibras. }\end{array}$ & 92,35 & 93,36 & $0,706^{\mathfrak{E}}$ \\
\hline 5.1. Catchup possui muito ou pouco sal (sódio)? & 39,44 & 55,94 & $<0,001^{\mathfrak{E}}$ \\
\hline 5.2. Presunto possui muito ou pouco sal (sódio)? & 73,64 & 87,73 & $<0,001^{£}$ \\
\hline 5.3. Vegetais cozidos possuem muito ou pouco sal (sódio)? & 78,47 & 83,10 & $0,155^{\mathfrak{E}}$ \\
\hline 5.4. Salsicha possui muito ou pouco sal (sódio)? & 76,66 & 88,73 & $<0,001^{£}$ \\
\hline 5.5. Macarrão instantâneo possui muito ou pouco sal (sódio)? & 70,82 & 78,87 & $\mathbf{0 , 0 0 4}{ }^{\mathfrak{E}}$ \\
\hline 5.6. Tempero industrializado possui muito ou pouco sal (sódio)? & 88,33 & 93,36 & $\mathbf{0 , 0 3 2 ^ { £ }}$ \\
\hline 5.7. Cheiro verde possui muito ou pouco sal (sódio)? & 73,04 & 77,06 & $0,170^{\mathfrak{E}}$ \\
\hline $\begin{array}{l}\text { 6. Quais os alimentos que são melhor aproveitados pelo organismo } \\
\text { para prevenir a anemia? }\end{array}$ & 7,04 & 17,51 & $<0,001^{\mathfrak{E}}$ \\
\hline 7. Qual dos alimentos não é uma boa fonte de gordura saudável? & 35,41 & 47,69 & $<0,001^{\mathfrak{E}}$ \\
\hline $\begin{array}{l}\text { 8. Quantas vezes, no mínimo, por dia, você acha que uma criança } \\
\text { deve comer frutas para ter boa saúde? }\end{array}$ & 1,41 & 19,52 & $<0,001^{£}$ \\
\hline $\begin{array}{l}\text { 9. Você costuma ler a informação nutricional e a data de validade } \\
\text { que está nos rótulos de alimentos industrializados? }\end{array}$ & 62,60 & 67,20 & $0,345^{\mathfrak{E}}$ \\
\hline Boas Práticas de Manipulação & & & \\
\hline $\begin{array}{l}\text { 10. Qual a diferença entre "limpar" e "desinfetar" uma superfície, } \\
\text { equipamento ou alimento? }\end{array}$ & 48,29 & 68,21 & $<0,001^{\mathfrak{E}}$ \\
\hline $\begin{array}{l}\text { 11. Você costuma higienizar os vegetais crus antes de serem } \\
\text { servidos? (alface, repolho, cheiro verde, couve manteiga, etc.) }\end{array}$ & 97,80 & 98,80 & $0,375^{¥}$ \\
\hline $\begin{array}{l}\text { 12. Como fazer o descongelamento de alimentos com segurança, } \\
\text { para o preparo no dia seguinte? }\end{array}$ & 77,87 & 91,55 & $<0,001^{\mathfrak{E}}$ \\
\hline $\begin{array}{l}\text { 13. Como deve ser preparada a solução clorada para desinfetar os } \\
\text { alimentos? }\end{array}$ & 63,98 & 73,84 & $<0,001^{\mathrm{E}}$ \\
\hline $\begin{array}{l}\text { 14. Como devem ser desinfetados os alimentos que são consumidos } \\
\text { crus? (ex. frutas e verduras) }\end{array}$ & 68,81 & 78,47 & $<0,001^{\mathfrak{E}}$ \\
\hline $\begin{array}{l}\text { 15. O que deve ser feito com alimentos que não são utilizados } \\
\text { totalmente e têm que voltar para o armazenamento? }\end{array}$ & 46,28 & 60,56 & $<0,001^{£}$ \\
\hline 16. Deve-se guardar a comida ainda quente na geladeira? & 3,82 & 51,11 & $<0,001^{\mathfrak{f}}$ \\
\hline $\begin{array}{l}\text { 17. O que você pode fazer para evitar o aparecimento de insetos na } \\
\text { cozinha? }\end{array}$ & 95,17 & 96,98 & $0,073^{\mathfrak{E}}$ \\
\hline $\begin{array}{l}\text { 18. Caso tenha formiga em seu alimento, você poderá comê-lo } \\
\text { tranquilamente sem risco de doenças. }\end{array}$ & 84,91 & 96,18 & $<0,001^{\mathfrak{E}}$ \\
\hline 19. Onde os microrganismos podem ser encontrados? & 77,26 & 92,96 & $<0,001^{\mathfrak{E}}$ \\
\hline $\begin{array}{l}\text { 20. Quais as recomendações para a entrada de pessoas que não } \\
\text { trabalham na cozinha? }\end{array}$ & 28,57 & 33,80 & $0,101^{\mathfrak{E}}$ \\
\hline $\begin{array}{l}\text { 21. Os manipuladores de alimentos devem lavar as mãos na área de } \\
\text { produção... }\end{array}$ & 14,08 & 15,49 & $0,236^{\mathfrak{E}}$ \\
\hline $\begin{array}{l}\text { 22. Como deve ser o manipulador de alimentos em relação a sua } \\
\text { aparência? }\end{array}$ & 72,64 & 81,29 & $\mathbf{0 , 0 0 2 ^ { \mathfrak { E } }}$ \\
\hline
\end{tabular}

Legenda: $£$ - teste de McNemar-Bowker; $¥$ - teste de McNemar-Bowker; valores considerados significativos com $p$ menor ou igual a 0,05 .

Fonte: Autores (2021).

De 15 itens respondidos no bloco temático AN, 11 (73,3\%) apresentaram diferença estatisticamente significativa entre o pré e o pós-teste. Quanto ao bloco BPM, de 13 itens respondidos, 9 (69,2\%) apresentaram diferença estatisticamente significativa. Destaca-se que as atividades do bloco temático AN foram executadas com maior abrangência de dinâmicas e 
menos exposições dialogadas.

Entre as perguntas do bloco temático AN, a dinâmica "Prato Saudável" pode ter contribuído no aumento significativo de respostas corretas assinaladas na questão 1, sendo a resposta "arroz, feijão, carne grelhada, salada de vegetais e frutas", mais completa nutricionalmente para representar uma opção de refeição saudável, escolhida por 96,78\% dos participantes no pósteste.

Quanto à maioria das demais questões, percebe-se que os assuntos contemplados nas dinâmicas "Teor de Açúcar dos Alimentos" e "Semáforo dos Alimentos" podem ter sido mais bem compreendidos e aplicados corretamente nas respostas ao pós-teste. Apontar que "salada de frutas" (questão 2) seria uma melhor opção de lanche saudável, que "catchup" (questão 5.1), "presunto" (questão 5.2), "salsicha" (questão 5.4), "macarrão instantâneo" (questão 5.5), "tempero industrializado" (questão 5.6) possuem alto teor de sal (sódio) e que "amendoim, peixe e azeite de oliva" (questão 7) são alimentos fonte de gorduras boas, demonstra maior entendimento sobre o maior teor de sal, açúcar e gorduras de alimentos ultraprocessados e a presença de gorduras "saudáveis" em alimentos in natura. Destaca-se a contribuição das dinâmicas citadas, além da exposição dialogada sobre DCNTs, na compreensão de que a alimentação não saudável pode configurar fator de risco para o desenvolvimento de "diabetes, hipertensão arterial e obesidade" (questão 3).

Importante ressaltar que a temática "anemia" foi abordada conforme a técnica tradicional de exposição de slides. Apesar disso, houve aumento significativo de respostas corretas entre o pré e o pós-teste. Sugere-se que essa diferença pode ter sido motivada pelo maior vínculo estabelecido entre os facilitadores e os participantes nas dinâmicas realizadas imediatamente antes, contribuindo na maior atenção ao tema. No pós-teste, 17,51\% dos participantes apontaram corretamente os alimentos “coração de frango, fígado, carne bovina" (questão 6) como sendo mais bem aproveitados pelo organismo para a prevenção da doença.

As questões 4, 5.3, 5.7, sem diferenças significativas entre o pré e o pós-teste, revelam altos percentuais de acertos mesmo no pré-teste, sugerindo-se que consistem em temáticas bem consolidadas pelo senso comum, como o entendimento de que "frutas, legumes e verduras são fontes de fibras e auxiliam no bom funcionamento intestinal" (questão 4) e também que alimentos in natura como "vegetais cozidos" (questão 5.3) e "cheiro verde" (questão 5.7) possuem baixo teor de sal (sódio).

Na questão 8, pode ser percebida a tendência de aumento de respostas abertas sinalizando maior quantidade de frutas a serem consumidas diariamente por crianças. As opções "não sei/não tenho certeza da resposta" (3,02\% / 2,21\%), "1 vez" (6,64\% / 4,02\%), "2 vezes" (50,70\% / 38,63\%) e "3 vezes" (33,40\% / 29,58\%) tiveram redução na quantidade de respostas, enquanto as opções "4 vezes" (4,43\% / 5,03\%), "5 vezes" (1,41\%/ 19,52\%), “6 vezes" $(0,20 \% / 0,60 \%)$ e " 8 vezes" $(0,20 \% /$ $0,40 \%$ ) tiveram aumento percentual. Ou seja, as dinâmicas abordando a temática alimentação saudável podem ter contribuído no entendimento de que frutas devem ser consumidas mais vezes ao dia.

Quanto à questão 9, sobre a leitura de rótulos dos alimentos, percebe-se que não foi encontrada diferença estatisticamente significativa entre as respostas do pré e pós-teste. Porém, houve diminuição na quantidade de participantes que respondeu que fazia a leitura "algumas vezes para alguns produtos" $(9,30 \% / 6,80 \%)$ ou que "só verifica a data de validade" $(25,60 \%$ / 22,90\%). Em contrapartida, a quantidade de participantes que respondeu "sim, verifico a data de validade e leio as informações nutricionais" $(62,60 \%$ / 67,20\%), a resposta mais adequada, aumentou. Sugere-se que a dinâmica "Análise de Rótulos de Alimentos" pode ter contribuído nessa mudança.

Conforme a observação dos facilitadores supõe-se também que há influência do menor nível de letramento e escolaridade dos participantes na verificação de informações nos rótulos alimentares. A temática "Rotulagem Nutricional" é alvo de amplas e constantes discussões que envolvem a perspectiva de ajustes para melhorar a compreensão dos consumidores sobre o que estão comprando e consumindo. A nova RDC nº 429/2020 (Brasil, 2020) que dispõe sobre a rotulagem nutricional dos alimentos embalados estabelece padrões atualizados, que devem vigorar a partir de 2022, para a disposição das 
informações nutricionais em modo frontal, além de alterações na legibilidade, no teor e no conteúdo das informações da tabela nutricional.

Entre as perguntas do bloco temático BPM, percebe-se que assuntos abordados sob exposição dialogada foram bem compreendidos e aplicados nas respostas corretas às questões. Temas tradicionais, explanados no terceiro dia de capacitação, como "diferença entre limpeza e desinfecção" (questão 10), "descongelamento correto dos alimentos" (questão 12), "desinfecção de frutas, legumes e verduras" (questões 13 e 14), "armazenamento correto dos alimentos" (questão 15 e 16), "microorganismos, DTAs e controle de perigos" (questões 18 e 19) e "higiene do trabalhador" (questão 22) obtiveram diferença estatisticamente significativa nas respostas entre o pré e o pós teste. Para as questões 15 e 16, pode ser acrescentada a contribuição dos conhecimentos repassados através da dinâmica "Organizando a Geladeira".

As questões 11 e 17, sem diferenças significativas entre o pré e o pós-teste, revelam altos percentuais de acertos mesmo no pré-teste, sugerindo-se que consistem em temáticas bem consolidadas, como o entendimento de que "sim, vegetais crus são costumeiramente higienizados antes de serem servidos" (questão 11) e que "manter a limpeza da cozinha evita o aparecimento de insetos" (questão 17).

Quanto às questões 20 e 21 , as quais abordavam as recomendações para a entrada de pessoas na cozinha e os momentos corretos para lavagem das mãos, a não observância de diferença significativa entre o pré e o pós-teste é atribuída ao tipo de metodologia utilizada na sua explicação. Nesse caso, a exposição dialogada não mostrou ser suficiente para facilitar a compreensão dos participantes quanto ao assunto. Para assuntos mais extensos e detalhados, técnicas ainda mais práticas, como simulações no local de trabalho ou em uma cozinha "modelo", poderiam ser mais bem aproveitadas. Por exemplo, uma simulação de atividades rotineiras com os momentos oportunos para lavagem das mãos, envolvendo a chegada do manipulador ao trabalho, a ida ao banheiro e retorno à manipulação dos alimentos, a manipulação do lixo após o preparo das refeições, poderia ajudá-los a apontar erros cometidos por eles próprios.

Considerando o questionário completo, ressalta-se que a quantidade de participantes que responderam "não sei/não tenho certeza" diminuiu em 25 (89,28\%) dos 28 itens. Dessa forma, é percebido que as atividades, teóricas e práticas, da capacitação podem ter contribuído nessa tendência, propiciando maior repertório de conhecimentos aos manipuladores de alimentos e consequente maior atitude em responder corretamente aos itens do questionário.

A Figura 2 apresenta a média de acertos nas questões de cada bloco temático antes e após serem abordados na capacitação e a média total de acertos no questionário.

Figura 2 - Distribuição percentual das médias de respostas corretas no questionário avaliativo segundo blocos temáticos. Fortaleza/CE. 2021.

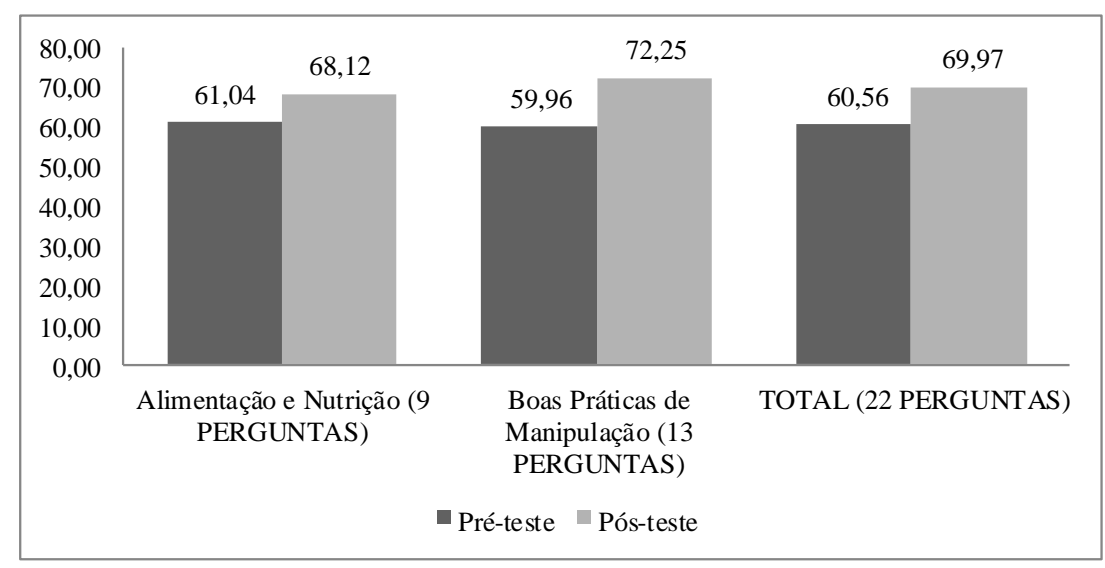

Fonte: Autores (2021). 
Após a realização do "Curso de Formação de Manipuladores de Alimentos de Escolas Municipais de Fortaleza", um maior percentual de respostas corretas, considerando tanto cada bloco temático quanto o questionário completo, sugere uma apreensão efetiva do conhecimento transmitido com incentivo à mudança de comportamento, resultado que corrobora com evidências da literatura.

Comparativamente, pesquisas internacionais realizadas com manipuladores de alimentos de restaurantes evidenciam pontuações de conhecimento alinhadas ao resultado do pós-teste encontrado nesta capacitação, o qual revelou 72,25\% de acertos na temática BPM. Questionários sobre segurança alimentar e higiene foram aplicados em Chicago, apresentando $71 \%$ de acertos (Panchal, Bonhote \& Dworkin, 2013), na Suíça, também 71\% (Panchal, Liu \& Dworkin, 2012), na Áustria, 76\% (Pichler, Ziegler, Aldrian \& Allerberger, 2014), na Sérvia, Grécia e em Portugal, 70,5\% (Smigic, Djekic, Martins, Rocha, Sidiropoulou \& Kalogianni, 2016) e na Irlanda, 73\% (Gruenfeldova, Domijan \& Walsh, 2019).

Um questionário aplicado antes e depois de uma capacitação em Boas Práticas de Manipulação de Alimentos (BPMA) para 60 manipuladoras de alimentos de escolas e creches públicas de Picuí - Paraíba demonstrou impacto positivo no conhecimento através do aumento da média de acertos entre antes $(59,16 \%)$ e depois $(71,83 \%)$ do treinamento (Oliveira Júnior, Lima Segundo \& Jerônimo, 2021).

Em Araraquara - São Paulo, um curso sobre Boas Práticas de Fabricação (BPF) para 192 manipuladores de alimentos de diversos serviços alimentícios demonstrou um maior percentual significativo de respostas corretas entre a avaliação diagnóstica do conhecimento e a avaliação final. Os temas "controle de temperatura" e "higiene ambiental" representaram a maior diferença de acertos entre as avaliações, sendo de $41 \%$ na avaliação diagnóstica e $81 \%$ na final e $50 \%$ na avaliação diagnóstica e 86\% na final, respectivamente (Devides, Maffei \& Catanozi, 2014).

Na região Sul, em três Restaurantes Universitários da Universidade Rio Grande, um treinamento sobre BPF para 12 manipuladores de alimentos, divididos em 4 grupos, apontou melhora do conhecimento através do aumento no percentual de acertos no questionário proposto antes e após sua realização. Nos grupos 1 e 3, que apresentaram respostas insatisfatórias (menor que 60\%) antes do treinamento, houve aumento de 31,3\% (G1) e de 25\% (G3) no percentual de acertos (Lopes et al, 2020).

Em pesquisa realizada até o momento, não foram encontrados muitos estudos que relatassem a experiência e os resultados de capacitações para manipuladores de alimentos abrangendo a temática Alimentação e Nutrição em associação a Boas Práticas de Manipulação. Para esse público, foram encontrados mais estudos enfatizando higiene dos alimentos, boas práticas e controle de qualidade.

De forma isolada, um ciclo de formação realizado entre 2013 e 2016 com manipuladores de alimentos de escolas municipais da Bahia explorou a temática "Flavonóides" com atividades teórico-práticas, abrangendo diagnóstico de conhecimento prévio, embasamento teórico, realização de oficinas e desenvolvimento de preparações alimentícias (Fonseca, Pamponet, Café, Lima \& Santos, 2017).

Importante salientar que a capacitação realizada no presente estudo envolveu não somente a temática BPM como também a temática AN, abrangendo atividades de educação alimentar e nutricional com o intuito de impactar positivamente nos hábitos alimentares dos manipuladores e, consequentemente, nos hábitos dos escolares atendidos por eles.

Transformações estruturais e relacionais no âmbito da educação podem permitir o desenvolvimento de atividades de incentivo à saúde, especialmente sobre EAN, dentro das escolas. Aproveitar o potencial do ambiente escolar, do PNAE e das "merendeiras" como conhecedoras do contexto alimentar dos alunos torna-se essencial (Fernandes, Fonseca \& Silva, 2014).

Em estudo qualitativo acerca das percepções e das ações sobre promoção da alimentação saudável realizadas por diversos atores da comunidade escolar, é reforçada a necessidade latente da inclusão das manipuladoras de alimentos nesse processo para que sejam oferecidas refeições saudáveis e condizentes com a realidade cultural dos alunos (Camozzi, Monego, 
Menezes \& Silva, 2015).

Entre manipuladores de alimentos que trabalham em grandes cantinas de escolas e fábricas em províncias do Vietnã, foi sugerido o maior enfoque prático dos treinamentos, envolvendo mais recursos visuais e discussões, além de menos exposições textuais (Vo, Le, Le, Minh \& Nuorti, 2015).

Capacitações mais frequentes, respeitando a complexidade e o tempo necessários, que avaliem e redirecionem conhecimentos através de metodologias envolventes, podem propiciar maior engajamento na prática adequada do manuseio de alimentos (Oliveira Júnior, Lima Segundo \& Jerônimo, 2021) e na melhora da qualidade nutricional das refeições.

E, para otimizar o engajamento nessas capacitações, a identificação inicial de falhas no conhecimento, atitudes e práticas realizadas pode pautar seu planejamento, execução e avaliação (Ncube, Kanda, Chijokwe, Mabaya \& Nyamugure, 2020; Auad et al., 2019).

Um questionário aplicado em manipuladores de alimentos de Restaurantes Populares do Rio Grande do Norte revelou uma correlação positiva entre o conhecimento e as práticas autorrelatadas: quanto maior a pontuação no conhecimento, maior nas práticas relatadas pelos manipuladores como sendo realizadas diariamente (Souza, Azevedo \& Seabra, 2018).

Possuir treinamento prévio em segurança alimentar foi determinante significativo para maiores chances de execução de boas práticas por manipuladores de alimentos etíopes, lotados em estabelecimentos alimentícios (Azanaw, Gebrehiwot \& Dagne, 2019).

Ou seja, capacitações bem planejadas e executadas são estratégia importante para propiciar o aporte e a aplicação prática de conhecimentos nas atividades profissionais de manipuladores de alimentos.

Quanto às técnicas utilizadas nessas capacitações, um estudo qualitativo, realizado com grupos focais de manipuladores de alimentos de escolas públicas para identificar a percepção de risco da SAN, evidenciou a insatisfação dos participantes com capacitações em moldes tradicionais, consideradas repetitivas e ultrapassadas ao desconsiderar as percepções e as vivências dos participantes e a baixa aplicabilidade das orientações à realidade do local (Machado, Monego \& Campos, 2014).

Desde a experiência de planejamento da capacitação realizada no presente estudo, foram percebidos benefícios em utilizar metodologias ativas para treinar manipuladores de alimentos. Para os graduandos e nutricionistas que pesquisaram e construíram tais metodologias e materiais, foram estimuladas maior criatividade e empatia em propor atividades atraentes, flexíveis e que permitissem o diálogo, a contribuição externa.

Na sua execução, com enfoque em boa comunicação e humanização dos indivíduos, foi percebido o maior envolvimento dos participantes, ao demonstrarem estar cada vez mais confortáveis para dar seu relato em um ambiente convidativo, estimulando a sociabilidade entre todos os presentes e a construção de saberes realmente conectados à prática rotineira.

A construção conjunta e significativa do conhecimento através de metodologias ativas e atrativas, representando novos referenciais pedagógicos, permite a ampliação de habilidades e possibilidades, com a promoção multiplicadora de mudanças (Roman et al., 2017; Gigante \& Campos, 2016).

Com essa construção conjunta, a relação entre participantes e facilitadores se estreita, pois ambos são favoráveis ao desenvolvimento do processo de ensino-aprendizagem, com autonomia, reflexão e participação, o que é aprendido e retido tem maiores chances de ser aplicado na prática (Roman et al., 2017).

Além de uma capacitação participativa, outros determinantes são importantes na mudança de comportamento incentivada e transferida do treinamento para a rotina diária (Auad et al., 2019), como o engajamento conjunto dos gestores do local para a construção de um ambiente organizacional que incentive a cultura positiva de segurança alimentar (Ncube, Kanda, Chijokwe, Mabaya \& Nyamugure, 2020). 
Nutricionistas, membros do Conselho de Alimentação Escolar (CAE) e gestores do PNAE no Rio de Janeiro destacaram que a contratação de mais nutricionistas para assumir a grande demanda de atividades representa um dos aspectos estratégicos para a melhora da qualidade do Programa (Ferreira et al., 2019).

A participação da SME no Curso é enaltecida, pois viabilizou o alcance de grande número de escolas e creches municipais e consequentemente de grande amostra de manipuladores de alimentos participantes. As nutricionistas da SME, responsáveis técnicas das escolas e creches, contribuíram decisivamente no planejamento de atividades, na construção de materiais mais didáticos e lúdicos e na execução das atividades expositivas.

Como limitações do estudo, apontamos a dificuldade de compreensão do questionário aplicado, sinalizando a importância da adequação das técnicas de capacitação ao nível de escolaridade e letramento funcional dos manipuladores de alimentos.

Outro fator limitante consistiu na impossibilidade da participação de todos os profissionais, em torno de 1200 manipuladores de alimentos, de todas as escolas e creches, considerando que o período de férias escolares é aproveitado para revezamento de férias entre eles, visando não desfalcar a equipe enquanto há alunos estudando e se alimentando.

Há a necessidade de maior periodicidade e organização dos treinamentos para que todos os manipuladores de alimentos sejam contemplados. Ainda assim, a amostra alcançada na realização desse Curso é bastante relevante, sendo maior do que a de vários estudos brasileiros abrangendo capacitações com avaliação pré e pós-teste (Oliveira Júnior, Lima Segundo \& Jerônimo, 2021; Lopes et al, 2020; Devides, Maffei \& Catanozi, 2014) e também estudos estrangeiros (Kunadu, Ofosu, Aboagye \& Tano-Debrah, 2016; Husain, Muda, Jamil, Hanafi \& Rahman, 2016).

Quanto à escolha do local para realizar a capacitação, estar fora do ambiente de trabalho mostrou ser interessante para interromper o padrão cansativo da rotina e aumentar a interatividade entre profissionais de diferentes instituições, aspectos percebidos na satisfação esboçada pelos participantes. Porém, durante a exposição das instruções normativas de BPM, os manipuladores relatavam diferentes dificuldades estruturais e operacionais em seus locais de trabalho, o que reforça a ideia de que a realização de capacitações no próprio ambiente de trabalho pode aumentar as chances de adequação à realidade de cada unidade e melhor apresentação de soluções específicas. Considerando os benefícios de ambos os locais, o planejamento de atividades que contemple as duas opções pode ser ainda mais vantajoso.

\section{Considerações Finais}

O "Curso de Formação de Manipuladores de Alimentos de Escolas Municipais de Fortaleza" realizou atividades sobre as temáticas Alimentação e Nutrição e Boas Práticas de Manipulação através de abordagens teórico-práticas, focando em estratégias educativas mais lúdicas e integrativas como oficinas, dinâmicas e discussões. Os facilitadores puderam perceber a satisfação e o engajamento dos participantes ao se manterem assíduos, atentos e dispostos a compartilhar experiências nas atividades.

O modelo de capacitação de manipuladores de alimentos proposto nesse estudo demonstrou melhora no desempenho do questionário avaliativo, com maior percentual de respostas corretas no pós-teste, sugerindo aumento do nível de conhecimento dos participantes. É reforçada, assim, a importância do desenvolvimento de capacitações que ampliem a utilização das diversas metodologias existentes focadas na problematização e no pensamento crítico.

Atividades de Extensão Universitária como esta podem ser cada vez mais valorizadas por agregarem benefícios para os diversos grupos que envolvem: alunos desenvolvendo diferentes habilidades para o exercício profissional e cidadão, profissionais reforçando sua prática ao compartilhar experiências e sociedade civil assimilando mais conhecimentos e melhorando sua qualidade de vida. 


\section{Referências}

Agência Nacional de Vigilância Sanitária. Ministério da Saúde. (2004). Cartilha sobre Boas Práticas para Serviços de Alimentação. Ministério da Saúde. https://saude.es.gov.br/Media/sesa/NEVS/Alimentos/cartilha_gicra_final.pdf.

Auad, L.I., Ginani, V.C., Stedefeldt, E., Nakano, E.Y., Nunes, A.C.S., \& Zandonadi, R. P. (2019). Food safety knowledge, attitudes, and practices of brazilian food truck food handlers. Nutrients, 11(8), 1784.

Azanaw, J., Gebrehiwot, M., \& Dagne, H. (2019). Factors associated with food safety practices among food handlers: facility-based cross-sectional study. BMC research notes, 12(1), 1-6.

BRASIL. Presidência da República. Casa Civil. Subchefia para Assuntos Jurídicos. Lei N N 11.947, de 16 de junho de 2009 . (2009). Dispõe sobre o atendimento da alimentação escolar e do Programa Dinheiro Direto na Escola aos alunos da educação básica. https://legislacao.presidencia.gov.br/atos/?tipo=LEI\&numero=11947\&ano=2009\&ato=359AzaE90dVpWTc00.

Brasil. Ministério da Saúde. Agência Nacional de Vigilância Sanitária - ANVISA. (2004). Dispõe sobre Regulamento Técnico de Boas Práticas para Serviços de Alimentação. Resolução da Diretoria Colegiada n $\mathrm{n}^{\circ} 216$ de 15 de setembro de $2004 . \quad$ Diário Oficial da União. Bhttps://bvsms.saude.gov.br/bvs/saudelegis/anvisa/2004/res0216_15_09_2004.html.

Brasil. Ministério da Saúde. (2005). Promoção do consumo de frutas, legumes e verduras: o programa "5 ao dia". http://www.rio.rj.gov.br/dlstatic/10112/126881/DLFE-2001.pdf/5aodia_1.pdf.

Brasil. Conselho Nacional de Saúde. (2013). Resolução n ${ }^{\circ} 466$, de 12 de dezembro de 2012. Aprova normas regulamentadoras de pesquisas envolvendo seres humanos. Brasília: Diário Oficial da União, 2013. https://bvsms.saude.gov.br/bvs/saudelegis/cns/2013/res0466_12_12_2012.html.

Brasil. Ministério da Saúde. (2014). Secretaria de Atenção à Saúde. Departamento de Atenção Básica. Guia alimentar para a população brasileira. Brasília: Ministério da Saúde, 2014. https://bvsms.saude.gov.br/bvs/publicacoes/guia_alimentar_populacao_brasileira_2ed.pdf.

Brasil. Ministério da Saúde. Agência Nacional de Vigilância Sanitária (ANVISA). (2020). Dispões sobre a rotulagem nutricional dos alimentos embalados. Resolução da Diretoria Colegiada $n^{\circ} 429$ de 08 de outubro de $2020 . \quad$ Diário Oficial da União. http://antigo.anvisa.gov.br/documents/10181/3882585/RDC_429_2020_.pdf/9dc15f3a-db4c-4d3f-90d8-ef4b80537380.

Camozzi, A. B. Q., Monego, E. T., Menezes, I. H. C. F., \& Silva, P. O. (2015). Promoção da Alimentação Saudável na Escola: realidade ou utopia? Cadernos Saúde Coletiva, 23(1), 32-37.

Da Silva, N., Junqueira, V. C. A., de Arruda Silveira, N. F., Taniwaki, M. H., Gomes, R. A. R., \& Okazaki, M. M. (2017). Manual de métodos de análise microbiológica de alimentos e água. Editora Blucher.

Del'Arcos, T., Santos, M. N., Gonçalves, M. G. S., Villanoeva, C. N. B. C., \& Dell'Isola, A. T. P. (2020). Avaliação higiênico-sanitária da água, bebedouros e manipuladores de alimentos em escola municipal. Revista UFG, 20. e20.62608.

Devides, G. G. G., Maffei, D. F., \& Catanozi, M. D. P. L. M. (2014). Perfil socioeconômico e profissional de manipuladores de alimentos e o impacto positivo de um curso de capacitação em Boas Práticas de Fabricação. Brazilian Journal of Food Technology, 17(2), $166-176$.

Fernandes, A. G. D. S., Fonseca, A. B. C. D., \& Silva, A. A. D. (2014). Alimentação escolar como espaço para educação em saúde. Ciência \& Saúde Coletiva, $19,39-48$.

Ferreira, C. A., de Lima, V. S., \& Aguiar, L. P. (2020). Condições higiênicos sanitárias dos serviços de alimentação no Brasil: uma revisão integrativa. Research, Society and Development, 9(10), e499108156-e499108156.

Ferreira, D. M., Barbosa, R. M. S., Finizola, N. C., Soares, D. S. B., Henriques, P., Pereira, S., Carvalhosa, C. S., Siqueira, A. B. F. S., \& Dias, P. C. (2019). Perception of the operating agents about the Brazilian National School Feeding Program. Revista de Saúde Pública, 53(34), 1-12.

Fonseca, K. Z., Pamponet, J. S. S., Café, A. G. M. P., Lima, C. L. B. \& Santos, I. P. (2017). Formação para manipuladores de alimentos: conhecimento sobre flavonoides e desenvolvimento de preparações para a alimentação escolar. Revista ELO - Diálogos em Extensão, 6(1), 35-45.

Garcia, M. V., \& Centenaro, G. S. (2016). Capacitação de manipuladores de alimentos e avaliação das condições higiênicas em serviço de alimentação. Brazilian Journal of Food Research, 7(2), 96-111.

Gigante, R.L., \& Campos, G.W.S. (2016). Política de formação e educação permanente em saúde no Brasil: bases legais e referências teóricas. Trabalho, Educação e Saúde, 14(3), 47-763.

Gruenfeldova, J., Domijan, K., Walsh, C. (2019). A study of food safety knowledge, practice and training among food handlers in Ireland. Food Control, 105, $131-140$.

Husain, N. R. N., Muda, W. M. W., Jamil, N. I. N., Hanafi, N. N. N., \& Rahman, R. A. (2016). Effect of food safety training on food handlers' knowledge and practices. British Food Journal, 118(4), 795-808.

Kunadu, A. P. H., Ofosu, D. B., Aboagye, E., \& Tano-Debrah, K. (2016). Food safety knowledge, attitudes and self-reported practices of food handlers in institutional foodservice in Accra, Ghana. Food Control, 69, 324-330.

Libermann, A. P., \& Bertolini, G. R. F. (2015). Tendências de pesquisa em políticas públicas: uma avaliação do Programa Nacional de Alimentação EscolarPNAE. Ciência \& Saúde Coletiva, 20, 3533-3546.

Lopes, A. C. D. C., Pinto, H. R. F., Costa, D. C. I. D. O., Mascarenhas, R. D. J., \& Aquino, J. D. S. (2015). Avaliação das B oas Práticas em unidades de alimentação e nutrição de escolas públicas do município de Bayeux, PB, Brasil. Ciência \& Saúde Coletiva, 20, 2267-2275. 
Lopes, L. C., Prestes, C. F., Mendes, L. G., de Paula, M., Augusto, M. M. M., \& da Cruz, W. S. (2020). Boas práticas de fabricação: treinamento aplicado aos manipuladores de alimentos de restaurante universitário. Brazilian Journal of Development, 6(7), 49282-49289.

Machado, M. G., Monego, E. T., \& Campos, M. R. H. (2014). Risk perception of food safety by school food-handlers. Journal of health, population, and nutrition, 32(1), 19 .

Ncube, F., Kanda, A., Chijokwe, M., Mabaya, G., \& Nyamugure, T. (2020). Food safety knowledge, attitudes and practices of restaurant food handlers in a lower-middle-income country. Food Sscience \& Nutrition, 8(3), 1677-1687.

Oliveira, A. S. D. S. S., Macedo, J. L., Pereira, I. C., Soares, E. L. P., de Oliveira Gomes, F., \& Assunção, M. D. J. S. M. (2019). Análise microbiológica de manipuladores e superfícies de manipulação de escolas públicas. Research, Society and Development, 8(3), e783830-e783830.

Oliveira Júnior, G. M. D., Lima Segundo, J. F., \& Jerônimo, H. M. A. (2021). Avaliação do nível de aprendizagem com manipuladores sobre boas práticas de manipulação de alimentos. Research, Society and Development, 10(1), e36310111796.

Pallos, T. D. B., Souza, R. A., Oberlender, G., Colpa, P. C., \& Bueno da Silva, D. (2020). Capacitação de Manipuladores de Alimentos: Metodologia Pedagógica Tradicional versus Metodologia Pedagógica Ativa. Brazilian Journal of Health Review, 3(4), 10736-10754.

Panchal, P. K., Liu, L., Dworkin, M. S. (2012). Food Safety Knowledge is Lower among Spanishspeaking Than among Englishspeaking Restaurant Food Handlers in Chicago. Food Protection Trends, 32(1), 16-25.

Panchal, P. K., Bonhote, P., Dworkin, M. S. (2013). Food Safety Knowledge among Restaurant Food Handlers in Neuchâtel, Switzerland. Food Protection Trends, 33(3), 133-144.

Pichler, J., Ziegler, J., Aldrian, U., Allerberger, F. (2014). Evaluating levels of knowledge on food safety among food handlers from restaurants and various catering businesses in Vienna, Austria 2011/2012. Food Control, 35(1), 33-40.

Pissaia, L. F., Del Pino, J. C., Quartieri, M. T., \& Marchi, M. I. (2018). Relato de experiência: qualificação da extensão universitária na área da saúde por meio de estratégias de ensino contemporâneas. Research, Society and Development, 7(2), e1172188-e1172188.

Rabelo, C. A. F., Mendes, A. E. P., Holanda, L. E. O., Souza, F. E. B., da Silva Lima, D., do Amaral, R. Q. G., \& de Sousa, P. H. M. (2020). Promoção da segurança alimentar e nutricional em escolas de ensino médio em tempo integral: relato de experiência extensionista. Research, Society and Development, 9(12), e13691210835-e13691210835.

Roman, C., Ellwanger, J., Becker, G. C., Silveira, A. D. D., Machado, C. L. B., \& Manfroi, W. C. (2017). Metodologias ativas de ensino-aprendizagem no processo de ensino em saúde no Brasil: uma revisão narrativa. Clinical and Biomedical Research.. 37(4), 349-357.

Santos, L. M. P., dos Santos, S. M. C. dos, Santana, L. A. A., Santos Henrique, F. C., Mazza, R. P. D., Santos, L. A. da S. \& dos Santos, L.S. (2007). Avaliação de políticas públicas de segurança alimentar e combate à fome no período 1995-2002. 4 - Programa Nacional de Alimentação Escolar. Cadernos de Saúde Pública, 23(11). 2681-2693.

Santos, J. L. G. D., Erdmann, A. L., Meirelles, B. H. S., Lanzoni, G. M. D. M., Cunha, V. P. D., \& Ross, R. (2017). Integração entre dados quantitativos e qualitativos em uma pesquisa de métodos mistos. Texto \& Contexto-Enfermagem, 26(3), e1590016.

Scarparo, A. L. S., Baldasso, P. L., Lopes, E. F.S., Rockett, F. C., \& Venzke, J. G. (2017). Aspectos relevantes na formação de manipuladores de alimentos que atuam na alimentação escolar. Revista Caderno Pedagógico, 14(2). 207-223.

Silva, S. U. D., Monego, E. T., Sousa, L. M. D., \& Almeida, G. M. D. (2018). As ações de educação alimentar e nutricional e o nutricionista no âmbito do Programa Nacional de Alimentação Escolar. Ciência \& Saúde Coletiva, 23, 2671-2681.

Smigic, N., Djekic, I., Martins, M. L., Rocha, A., Sidiropoulou, N. \& Kalogianni, E.P. (2016). The level of food safety knowledge in food establishments in three European countries. Food Control, 63, 187-194.

Soares, D. D. S. B., Henriques, P., Ferreira, D. M., Dias, P. C., Pereira, S., \& Barbosa, R. M. S. (2018). Boas Práticas em Unidades de Alimentação e Nutrição Escolares de um município do estado do Rio de Janeiro-Brasil. Ciência \& Saúde Coletiva, 23, 4077-4083.

Souza, C. V. S. D., Azevedo, P. R. M. D., \& Seabra, L. M. A. J. (2018). Food safety in Brazilian popular public restaurants: Food handlers' knowledge and practices. Journal of Food Safety, 38(5), e12512.

Souza, A. S., \& Campos, L. B. P. (2019). Habilidades transversais de engenheiros em formação: o papel de projetos de extensão. Research, Society and Development, 8(4), e684712.

Valentim, I. M., Dias, L. M., \& Paixão, R. M. S. (2019). Agenda 2030 para o Desenvolvimento Sustentável: Um estudo sobre a implementação dos ODS de 1 ao 4 no Brasil. Fronteira, Belo Horizonte, 18(36), 233-256.

Villar, B. S., Schwartzman, F., Januario, B. L., Ramos, J. F. (2013). Situação dos municípios do estado de São Paulo com relação à compra direta de produtos da agricultura familiar para o Programa Nacional de Alimentação Escolar (PNAE). Revista Brasileira de Epidemiologia, 16(1), 223-226.

Vo, T. H., Le, N. H., Le, A. T. N., Minh, N. N. T. \& Nuorti, J. P. (2015). Knowledge, attitudes, practices and training needs of food-handlers in large canteens in Southern Vietnam. Food Control, 57, 190-194. 